TWO METhods OF ESTIMATING WATER IN CRUDE PETROLEUM, ETC. 529

\title{
TWO RAPID METHODS OF ESTIMATING WATER IN CRUDE PETROLEUM, OIL-FUEL, AND SIMILAR SUBSTANCES.
}

By HERBERT S. SHREWSBURY, F.I.C.

(Read at the Meeting, November 4, 1914.)

THE author has devised the following methods in view of the fact that those generally in use are tedious, lengthy, and not very accurate.

I. Distimlation Process.-The only novelty in the method is the apparatus devised, which it is hoped will be found simple and effective.

A 500 c.c. distillation-flask is supported with its side-tube at right angles to the bench and inserted to the neck in a 25 c.c. cylinder, graduated in tenths or, better, in twentieths, with a bore not much greater than that of the side-tube. The cylinder is supported in a vessel provided with an outlet at the bottom, through which water is passed at such a rate as to keep the level constant within a few millimetres of the top. Such an arrangement forms an efficient combination of condenser and receiver, and practically eliminates any loss of water.

One hundred c.c. of oil (or a volume equivalent to 100 grms. calculated from the sp. gr.) are placed in the flask with a few pieces of dry pumice. The neck and surface of the flask (uncovered by the oil) are now heated by a Bunsen flame, the flame being kept in continual movement playing over the surface of the glass. In this way these portions of the flask (commencing from the neck close to the cork) are kept at such a temperature that no water can condense inside the flask; the heating is continued from above downwards, with occasional heating below the oil surface.

By careful manipulation it is possible to drive off all the water, and the process is finished by distilling several c.c. of the oil itself. No drops of water should be allowed to condense and roll down into the hot oil, as this is liable to cause violent bumping. If necessary, on account of the percentage of water present, a larger receiver may be used, or it may be changed for others of the same size. It is of course necessary to keep the side-tube of the flask above the level of the distillate. 


\section{SHREWSBURY : TWO RAPID METHODS OF ESTIMATING WATER}

The distillate is finally rapidly rotated, to assist the settling of the water, which may be further accelerated by the addition of dry petroleum ether. When no further increase in its volume is observed, the percentage of water is read.

II. Turbidity Temperature Process.--This method depends on: (1) The possibility of extracting water from oil-fuel with glacial acetic acid; (2) the delicacy with which the turbidity temperature of glacial acetic acid and a standard oil responds to minute percentages of water.

The method has been found to agree well with the distillation process. The main disadvantages are the preparation of a standard oil and the necessity of making careful standards for every new stock of glacial acetic acid. The turbidity temperatures do not vary with increase of water as regularly as one would wish, but by making a table of standards in tenths per cent. of water from $0-2.6$ per cent., it is possible to obtain a water percentage very near to the trutb. The irregularity of the figures may be due to the difficulty of determining the exact turbidity-point. It is the author's practice to note the temperature at which the mixture becomes suddenly and markedly turbid. This point is slightly below the temperature of first faint turbidity. A suitable standard oil (giving a turbidity temperature of $49^{\circ} \mathrm{C}$. with glacial acetic acid) was made by mixing equal volumes of arachis and coconut oils, the latter of which is truly an oil at tropical temperatures.

A correction is necessary for the effect on the turbidity temperature of substances other than water dissolved from the oil fuel. This is made by obtaining a blank on the oil previously dried by boiling for a short time in an open dish. When the standards are prepared, an estimation may be made in less than ten minutes.

Description of Method.-Ten c.c. of standardised glacial acetic acid are placed in a dry, stoppered, graduated 25 c.c. cylinder and 10 c.c. of the oil-fuel are added. The cylinder is shaken and its contents transferred to a dry separator. The acetic acid extract is separated and passed through a dry filter, and 2 c.c. of the filtrate are heated with 2 c.c. of the standard oil in a test-tube until the mixture is clear. (The heating is conveniently effected by a spirit lamp.)

A thermometer is inserted in the clear fluid and the turbidity temperature observed in the usual way. After subtracting the blank, which is obtained by similarly treating 10 c.c. of the dried oil and subtracting from the turbidity temperature obtained that of the standard acetic acid, reference to the standards gives a direct reading of the weight of oil in 100 volumes of the oil, and the figure may be calculated to a percentage by use of the sp. gr. of the oil. With oils of a sufficiently similar nature, a constant blank may be used. When the percentage of water is above 2.5 , it is necessary to dilute the acetic acid extract with standard glacial acetic acid, exactly the same dilution being made of the extract which gives the figure for the blank. In these cases, after subtracting the blank, the water percentage indicated by the table is multiplied by the ratio of dilution.

Turbidity Temperature of Standards. - The following table shows some turbidity temperatures of the oil mixture mentioned and some standards prepared from a sample of glacial acetic acid. It is, of course, necessary for each analyst to fix his own standards, and these would have to be freshly prepared for every new stock of glacial acetic acid. 
Acetic Acid Standard.

Per Cent. of Water added.

$\begin{array}{llllll}\text { Nil } & \ldots & \ldots & \ldots & \ldots & 49 \\ 0.5 & \ldots & \ldots & \ldots & \ldots & 63 \\ 1 \cdot 0 & \ldots & \ldots & \ldots & \ldots & 74 \\ 1 \cdot 1 & \ldots & \ldots & \ldots & \ldots & 75 \\ 1.2 & \ldots & \ldots & \ldots & \ldots & 76 \\ 1.3 & \ldots & \ldots & \ldots & \ldots & 79 \\ 1.4 & \ldots & \ldots & \ldots & \ldots & 82 \\ 1.5 & \ldots & \ldots & \ldots & \ldots & 86 \\ 1.6 & \ldots & \ldots & \ldots & \ldots & 88 \\ 1.7 & \ldots & \ldots & \ldots & \ldots & 90 \\ 2 \cdot 0 & \ldots & \ldots & \ldots & \ldots & 93\end{array}$

It will be seen that the average increase in turbidity temperature is $2 \cdot 2^{\circ} \mathrm{C}$. per tenth per cent. of water.

An extract of dried oil fuel made with the same glacial acetic acid in the way described gave a turbidity temperature of $57.5^{\circ} \mathrm{C}$., furnishing a blank of $8.5^{\circ} \mathrm{C}$.

Comparison of Methods. - The following comparative results were obtained by the two methods for various samples of crude petroleum :

$\begin{array}{lcc}\text { Sample. } & \text { Distillation Method. } & \begin{array}{c}\text { Percentage of Water. } \\ \text { Turbidity Temperature } \\ \text { Method. }\end{array} \\ \text { A } & 0.00 & 0.00 \\ \text { B } & 0.23 & 0.23 \\ \text { C } & 1.00 & 1.15 \\ \text { D } & 1.40 & 1.45 \\ \text { E } & 2 \cdot 65 & 2.58 \\ \text { ining 1 per cent. water } & 1.00 & 1.30 \\ \text { ining 10 per cent. water } & 9.70 & 10.00\end{array}$

Preparation containing containing 10 per cent. water $9 \cdot 70$

10.00

Application of Methods to Other Substances. - Both methods are probably applicable (with modifications unessential in principle) to the estimation of water in butter, margarine, lard, and other oils and fats, and generally to substances immiscible with water and capable of distillation, or substances from which water may be removed by extraction with glacial acetic acid.

Government Laboratory,

TRINIDAD, B.W.I.

\section{Discussion.}

Mr. G. N. Huntuy said that he had used a direct distillation method somewhat similar to, but rather more elaborate than, the one now described. The distillation was carried out in a current of air, the main fraction being collected in freezing mixture and the rest in drying tubes. This was an accurate method, but tedious. Another method which was said to be a good one was the toluene method. About $\frac{1}{2}$ litre of the oil (the quantity depending upon the proportion of water expected) was distilled with about 100 c.c. of toluene, the distillate being collected in a graduated tube. When checked by the addition of known quantities of water to dry oil, this method was shown to be accurate practically to within 0.01 per cent., depending on the graduation of the tube. It was not quite so good as the direct 
distillation method for crude oil, because in that case the meniscus did not form well and was difficult to read accurately.

Dr. Lessing said that from a comparison of the figures, it would seem very much simpler to use the distillation method than the turbidity method, which latter seemed rather complicated and necessitated constant preparation of fresh standards. In the distillation method, however, when the water was present only in minute traces-less than 0.1 per cent.-the distilled oil absorbed almost as nuch water as was separated; and the same applied to the toluene method or any method in which a lighter oil was used. These methods had been used a good deal not only for oil but for coal ; and the necessity had been shown by Constam and by Marcusson, and was confirmed by experiments which he himself had made, that the toluene or sylene, or whatever light oil was used, should have a definite moisture content. It was best to distil the oil with water before each determination, so that it assumed a certain degree of moisture, and did not absorb any of the moisture that was driven off. Attention was drawn to Sanders' method, recently described in the Journal of the Chemical Society. 